\title{
Real time robustness test evaluation performance for intelligent fuzzy controller in extraction process
}

\author{
Z. M. Yusoff ${ }^{1}$, Nur Dalila Khirul Ashar ${ }^{2}$, Zuraida Muhammad ${ }^{3}$, Amar Faiz Zainal Abidin ${ }^{4}$, \\ Noor Fadzilah Razali ${ }^{5}$, Shakira Azeehan Azli ${ }^{6}$, A.M. Markom ${ }^{7}$, Khairul Kamarudin Bin Hasan \\ ${ }^{1,2,5,6,7,8}$ Faculty of Electrical Engineering, Universiti Teknologi MARA, Malaysia \\ ${ }^{3}$ Faculty of Electrical Enigneering, Universiti Teknologi MARA, Malaysia \\ ${ }^{4}$ Faculty of Electrical, Universiti Teknikal Malaysia Melaka, Malaysia
}

\begin{abstract}
Article Info
Article history:

Received Jan 3, 2019

Revised Apr 2, 2019

Accepted Apr 23, 2019

\section{Keywords:}

Essential oil

Extraction process

Fuzzy controller

Real time

Robustness test

ABSTRACT

This paper presents the real time robustness test using intelligent fuzzy based controller in extraction process of essential oil is discussed in this study. Previous finding shows that the quality of the essential oil is affected by the steam temperature that acts as the control variable in this study. The robustness test is applied to the system during running process to show the system is robust to any operation conditions $t$ make sure the controller is able to give a smooth control output response. The dynamic performance of the system are represented by applying standard performance criteria such as rise time $\mathrm{Tr}$, settling time Ts, overshoot \%OS, root mean square error (RMSE) and time on recovering load disturbance. Generally, the objectives in designing the controllers have been achieved because all intelligent fuzzy based controllers capable to regulate the desired set point by acting on the change in the output compared with the set point.
\end{abstract}

\section{Corresponding Author:}

Zakiah Mohd Yusoff,

Faculty of Electrical Engineering,

Universiti Teknologi MARA, Cawangan Johor,

Kampus Pasir Gudang, 81750 Masai, Johor, Malaysia.

Email: zakiah9018@johor.uitm.edu.my
Copyright @ 2019 Institute of Advanced Engineering and Science. All rights reserved.

\section{INTRODUCTION}

It is very important to consider the robustness test as well as performance in control system design [1-6]. Generally, robustness test is applied to provide controller that can produce a smooth control response and also robust to any changes of the operation conditions during running process [7-10]. Each process is tested on a robustness test which specifies on set point changes and load disturbance. The objective of the set point changes is to force the output of the proposed controller to follow the new set point either by increasing or decreasing the new set point through minimizing the error between the reference and actual signal [7, 9]. Meanwhile, the aim of the load disturbance test is to analyze the capability of the intelligent fuzzy based controller in facing any noise or disturbance [4]. Many types of disturbances can be applied such as the increase of the water flow rate through the distillation column that can affect the process [7], a combination of white noise and sine-wave noise [11] and changes to the composition of raw materials. Numerous works applied the robustness test to check the capability and performance of their proposed controller for the process [3, 12-16].

Controller performance is used to evaluate the controller response by measuring the step response of the controller. The good controller is defined as a controller that could minimize the error between desired target and output in the steady-state manner [17]. The standard performance indexes used in the system's step response are percentage overshoot, rise time, settling time and accumulated error [3-7,18-19]. The percentage overshoot is the percentage of the maximum excess value versus the final value. The rise time is the time for 
the step response to reach from 0 to its final value. The accumulated error is the summation of the absolute error of the step response at the sampling instants [19]. The settling time is the time taken to attain the nearly constant value of set point [19-21]. This performance index was applied to many applications and it is desirable to optimize a number of different system performances to meet some requirements such as smaller overshoot, minimizing the settling time of the output, fast rise time, smaller steady-state error and the smaller load effect [19].

\section{RESEARCH METHODOLOGY}

Robustness test for real time performance was done using two intelligent fuzzy based controllers which are hybrid fuzzy PID controller (HFPID) and self-tuning fuzzy PID controller. These two controllers were attached to the extraction process in order to control the steam temperature. Each process is tested on a robustness test which is set point changes and load disturbance. There are three set point tracking set which are at $60 \mathrm{oC}, 80 \mathrm{oC}$ and $90 \mathrm{oC}$. $10 \mathrm{oC}$ of the disturbance is injected on 5000th sample onwards from the set point. The controller's design robustness is measured by the rapidness of the output returns from the desired point. The objective of the disturbance test is to analyze the controller's optimum ability and its performance to recover load disturbance in the least time possible with introduced upset conditions. Generally, the purpose of the robustness test is to analyse the capability of each controller in adapting the disturbance during running process. The controller can be said to be robust if it is able to track the desired set point in all situations even when set point changes and can cause an abrupt disturbance during running process. The details of intelligent fuzzy controller configuration can be found in [3, 23-26]

\section{RESULTS AND ANALYSIS}

\subsection{Set Point Test}

The result for intelligent fuzzy based controller using PID, HFPID using 7 membership function and STFPID for 5 membership function is shown in Figure 1. The result shows that all the controllers are able to track the set point changes by producing excellent performance in terms of rise time, settling time and \%OS. All controllers are able to meet the desired set point with HFPID-7 and STFPID-5 shows the outperform result as compared with the PID. However, the PID controller provides comparable performance of RMSE value as HFPID-7 and STFPID-5.

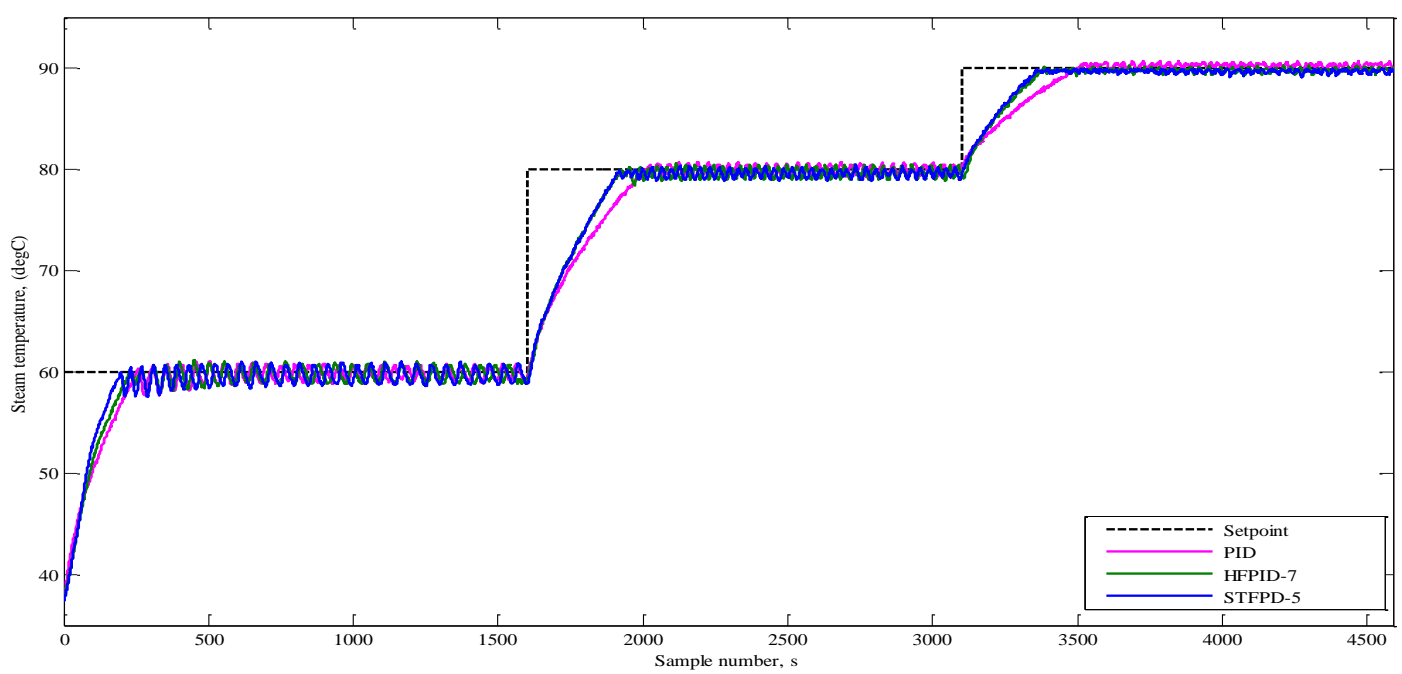

Figure 1. Set point test

The evaluation result for real time set point tracking at $60 \mathrm{oC}$ is tabulated in Table 1 . Based on analysis, it shows that at set point $60 \mathrm{oC}$, the self-tuning fuzzy-5 provides superior result as compared with PID and HFPID-7 controller. The STFPID-5 provides $129 \mathrm{~s}$ of rise time, $1581 \mathrm{~s}$ of settling time, 0.8354 of $\% \mathrm{OS}$ and 0.7372 of RMSE. This result shows that STFPID-5 outperformed than others controller by producing the rise time less $62 \mathrm{~s}$, settling time less $13 \mathrm{~s}$, \%OS less 0.2754 and RMSE less -0.0243 than PID 
controller. The HFPID-7 also produced very encouraging results where the rise time less $60 \mathrm{~s}$, settling time less 3 s, \%OS less 0.1998 and RMSE less -0.0574 than the PID controller. The STFPID-5 also produced comparable performance of rise time with a HFPID-7 controller. However, the settling time, \%OS and RMSE shows that STFPID-5 is better compared with HFPID-7 with settling time less $10 \mathrm{~s}$, \%OS less 0.0756 and RMSE less 0.0331 than HFPID-7.

Table 1. Comparison of Real Time Performance of PID, HFPID-7, and STFPID-5 on Set Point Test

\begin{tabular}{cccccc}
\hline \multicolumn{7}{c}{ (Set Point 60 oC) } \\
\hline No & Controller & Rise time, $(\mathrm{s})$ & Settling time, $(\mathrm{s})$ & \%OS & RMSE \\
\hline 1 & PID & 191 & 1594 & 1.1108 & 0.7129 \\
2 & HFPID-7 & 131 & 1591 & 0.9110 & 0.7703 \\
3 & STFPID-5 & 129 & 1581 & 0.8354 & 0.7372 \\
HFPID-7 compared with PID & $60 \mathrm{~s}(1 \mathrm{~min})$ & $3 \mathrm{~s}$ & 0.1998 & -0.0574 \\
STFPID-5 compared with PID & $62 \mathrm{~s}(>1 \mathrm{~min})$ & $13 \mathrm{~s}$ & 0.2754 & -0.0243 \\
STFPID-5 compared with HFPID-7 & $2 \mathrm{~s}$ & $10 \mathrm{~s}$ & 0.0756 & 0.0331 \\
\hline
\end{tabular}

Table 2 shows the detail analysis for comparison of PID, HFPID-7, and STFPID-5 controllers to track the set point change (at set point $80 \mathrm{oC}$ ). Based on the analysis, it shows that at set point $80 \mathrm{oC}$, the STFPID-5 provides the best performance compared with other controllers. The STFPID-5 provides $245 \mathrm{~s}$ of rise time, $1484 \mathrm{~s}$ of settling time, 0.4953 of \%OS and 0.5677 of RMSE. The rise time, settling time, \%OS and RMSE for PID controller is 328 s, 1495 s, $0.7462 \%$ OS and 0.4087 , respectively. This result shows that the rise time, settling time, \%OS and RMSE for STFPID-5 is $83 \mathrm{~s}, 11 \mathrm{~s}, 0.2509$ and -0.1590 less than PID controller. The HFPID-7 provides $247 \mathrm{~s}$ of rise time, $1495 \mathrm{~s}$ of settling time, 0.5047 of $\%$ OS and 0.5566 of RMSE. The difference between STFPID-5 and HFPID-7 is $2 \mathrm{~s}, 11 \mathrm{~s}, 0.0094$ and -0.0111 for rise time, settling time, \%OS and RMSE, respectively. The STFPID-5 was produced comparable performance of rise time and settling time with a HFPID-7 controller. Meanwhile, the PID controller performed the best performance at steady-state by producing the lowest RMSE.

Table 2. Comparison of Real Time Performance of PID, HFPID-7, and STFPID-5 on Set Point Test (Set Point $80 \mathrm{oC}$ )

\begin{tabular}{cccccc}
\hline No & Controller & Rise time, $(\mathrm{s})$ & Settling time, $(\mathrm{s})$ & \%OS & RMSE \\
\hline 1 & PID & 328 & 1495 & 0.7462 & 0.4087 \\
2 & HFPID-7 & 247 & 1495 & 0.5047 & 0.5566 \\
3 & STFPID-5 & 245 & 1484 & 0.4953 & 0.5677 \\
HFPID-7 compared with PID & $81 \mathrm{~s}(>1 \mathrm{~min})$ & - & 0.2415 & -0.1479 \\
STFPID-5 compared with PID & $83 \mathrm{~s}(>1 \mathrm{~min})$ & $11 \mathrm{~s}$ & 0.2509 & -0.1590 \\
STFPID-5 compared with HFPID-7 & $2 \mathrm{~s}$ & $11 \mathrm{~s}$ & 0.0094 & -0.0111 \\
\hline
\end{tabular}

Table 3 tabulated the analysis for comparison of real time performance of PID, HFPID-7, and STFPID-5 controller at set point tracking 90 oC. Overall, the result shows that at set point 90 oC, the STFPID-5 provides the outperformed performance compared with PID and HFPID-7 controller. The rise time, settling time, \%OS and RMSE for PID controller is 334 s, 1496 s, $0.6723 \%$ OS and 0.3135 , respectively. The HFPID-7 provides $216 \mathrm{~s}$ of rise time, $1497 \mathrm{~s}$ of settling time, 0.3371 of $\% \mathrm{OS}$ and 0.2851 of RMSE. Meanwhile, the STFPID-5 provides $206 \mathrm{~s}$ of rise time, $1478 \mathrm{~s}$ of settling time, 0.3249 of \%OS and 0.3040 of RMSE. This result shows that the rise time, settling time, \%OS and RMSE for STFPID-5 is $128 \mathrm{~s}$, $18 \mathrm{~s}, 0.3474$ and 0.0095 less than PID controller. The difference between STFPID-5 and HFPID-7 is $10 \mathrm{~s}, 19$ s, 0.0122 and -0.0189 for rise time, settling time, \%OS and RMSE, respectively.

Table 3. Comparison of Real Time Performance of PID, HFPID-7, and STFPID-5 on Set Point Test

\begin{tabular}{cccccc}
\multicolumn{7}{c}{ (Set Point 90 oC) } \\
\hline No & Controller & Rise time, $(\mathrm{s})$ & Settling time, $(\mathrm{s})$ & \%OS & RMSE \\
\hline 1 & PID & 334 & 1496 & 0.6723 & 0.3135 \\
2 & HFPID-7 & 216 & 1497 & 0.3371 & 0.2851 \\
3 & STFPID-5 & 206 & 1478 & 0.3249 & 0.3040 \\
HFPID-7 compared with PID & $118 \mathrm{~s}(>1 \mathrm{~min})$ & $-1 \mathrm{~s}$ & 0.3352 & 0.0284 \\
STFPID-5 compared with PID & $128 \mathrm{~s}(>2 \mathrm{~min})$ & $18 \mathrm{~s}$ & 0.3474 & 0.0095 \\
STFPID-5 compared with HFPID-7 & $10 \mathrm{~s}$ & $19 \mathrm{~s}$ & 0.0122 & 0.0189 \\
\hline
\end{tabular}




\subsection{Load disturbance}

Figure 2 shows a comparison performance for disturbance test among 3 different implemented controllers that was attached to the extraction system.

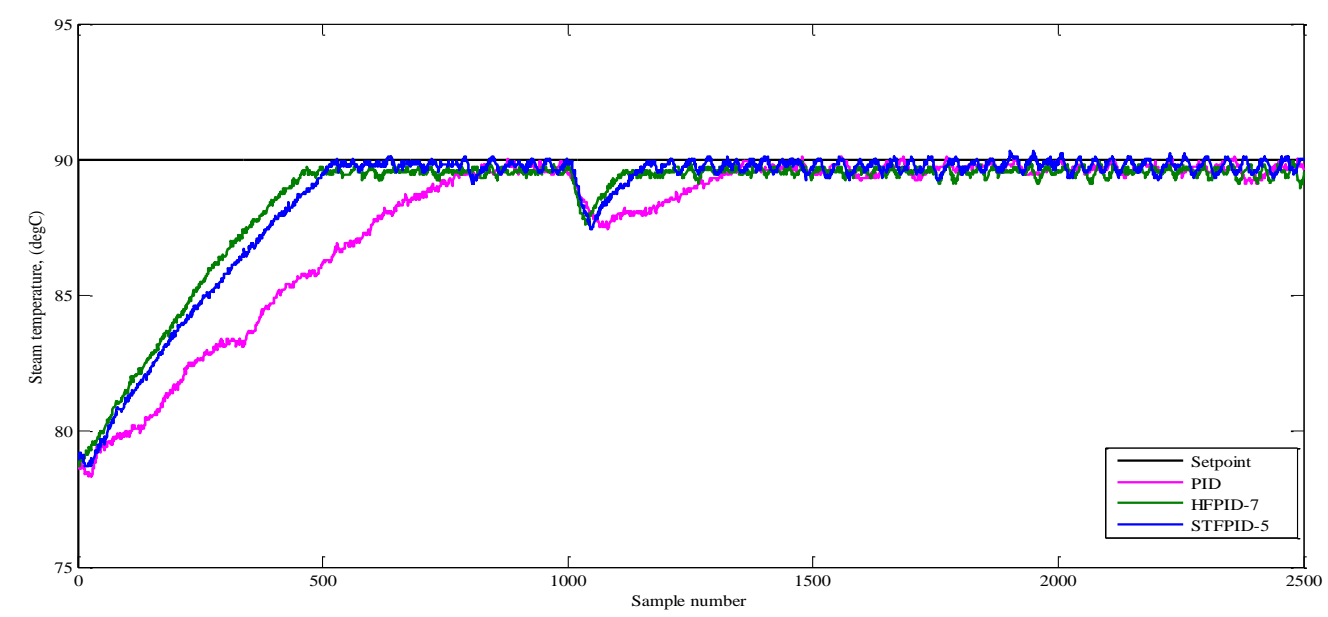

Figure 2. PID, HFPID-7 and STFPID-5 performance on recovering load disturbance

Table 4 summarized the results for real time performance of PID, HFPID-7 and STFPID-5 controllers on recovering load disturbance, whereas Figure 3 shows the comparison of speed which the output returns to the set point for all proposed controllers. From the result in the Table 4, after introducing the disturbance at sample 1000th, steam temperature decreases with $\mathrm{Tmin}=87.42 \mathrm{oC}$, Tmin $=87.50 \mathrm{oC}$ and Tmin $=87.42 \mathrm{oC}$ for proposed PID, HFPID-7 and STFPID-5 controllers, respectively. All controllers shows the capability of correcting the process disturbances and compensating for the errors by capturing back the set point after the system was disturbed during running process. However, these results revealed that the good robustness of the HFPID-7 and STFPID-5 controllers since PID controller took the longest time to recover from the upset caused by a process disturbance with $386 \mathrm{~s}$. The time taken to capture back the set point after introduced disturbance for HFPID-7 controller using 49 rules is five times faster, which is only $74 \mathrm{~s}$ as compared with PID controller with $386 \mathrm{~s}$. The recovery process is significantly shortened for HFPID-7 by taking 312 s less than PID controller. Significant improvement can be spotted for HFPID-7 controller because it provides speedy recovery and robust response in comprising an abrupt disturbance during running process. The results also demonstrate that the STFPID- 5 offer better performance by greatly improve the recovery process compared with PID controller. The STFPID-5 takes $285 \mathrm{~s}$ less than PID controller. On the other hand, the control signals for all proposed controllers display similar patterns. The control signal varies between $0 \mathrm{~V}$ to $5 \mathrm{~V}$ at a steady-state. However, when subjected to load disturbance at 1000th samples, the control signal maintained at $5 \mathrm{~V}$. The developed controllers pushed the steam temperature to return to the set point as fast as possible.

Table 4. Analysis for Disturbance Test

\begin{tabular}{cccc}
\hline No & Controller & $\mathrm{T}_{\min }$ & Recovery time (s) \\
\hline 1 & PID & $87.42{ }^{\circ} \mathrm{C}$ & 386 \\
2 & HFPID-7 & $87.50{ }^{\circ} \mathrm{C}$ & 74 \\
3 & STFPID-5 & $87.42{ }^{\circ} \mathrm{C}$ & 101 \\
HFPID-7 compared with the PID & -312 \\
HFPID-7 compared with the STFPID- & -27 \\
5 & \\
\multicolumn{4}{l}{ STFPID-5 compared with the PID } \\
\hline
\end{tabular}

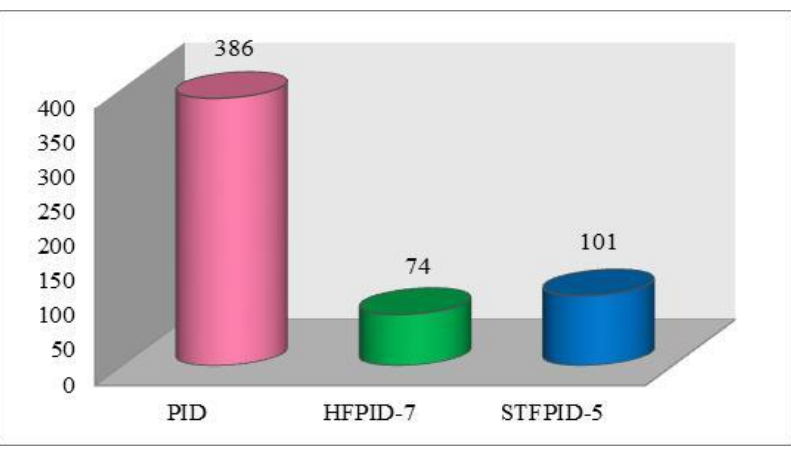

Figure 3. Graphical comparison of recovery time for all proposed controllers 


\section{CONCLUSION}

Generally, the objectives in designing the controllers have been achieved since all the implemented fuzzy based controller manage to regulate the desired steam temperature at desired set point by acting on the change in the output compared with the set point. This study has shown that PID, HFPID-7 and STFPID-5 controller have the ability to curb the disturbance that has been suddenly interrupted during running process.

\section{ACKNOWLEDGEMENTS}

It is acknowledged that this project is supported by UiTM Kampus Pasir Gudang, and FRGS under project code: 600-IRMI/FRGS 5/3 (154/2019).

\section{REFERENCES}

[1] M. C. Palframan, et al., "Robustness Analysis of Flight Controllers for Fixed-Wing Unmanned Aircraft Systems Using Integral Quadratic Constraints," in IEEE TRANSACTIONS ON CONTROL SYSTEMS TECHNOLOGY, 2017, pp. 86-102.

[2] Z. Muhammad, et al., "Application of Self-Tuning Fuzzy PID (STFPID) Controller on Industrial Essential Oil Extraction System using System Identification Approach," Journal of Telecommunication, Electronic and Computer Engineering (JTEC), vol. 10, pp. 51-55, 2018.

[3] Z. M. Yusoff, et al., "Hybrid Fuzzy Plus PID Controller of Hydro-Diffusion Steam Distillation Essential Oil Extraction System: Design and Performance Evaluation," AIP Conference Proceedings, vol. 1774, 2016.

[4] Pan and S. Das, "Fractional Order Fuzzy Control of Hybrid Power System with Renewable Generation using Chaotic PSO," ISA Transactions, vol. 62, pp. 19-29, 2016.

[5] J.-S. Hu, et al., "Robust Yaw Stability Control for In-Wheel Motor Electric Vehicles," ASME Transactions on Mechatronics vol. 22, pp. 1360-1370, 2017.

[6] S. M. A. SHAH, et al., "Robustness Testing of Embedded Software Systems: An Industrial Interview Study," IEEE Access, vol. 4, pp. 1859-1871, 2016.

[7] Z. M. Yusoff, et al., "Steam Temperature Control of Hydro-Diffusion Essential Oil Extraction System using Hybrid-Fuzzy Plus PID Controller," in 2014 IEEE Conference on Systems, Process and Control (ICSPC 2014), 2014, pp. 105-110.

[8] B. Meghni, et al., "A Second-Order Sliding Mode and Fuzzy Logic Control to Optimal Energy Management in Wind Turbine with Battery Storage," Neural Computing and Applications, vol. 28, pp. 1417-1434, 2017.

[9] L. Suna, et al., "Multi-Objective Optimization for Advanced Superheater Steam Temperaturecontrol in A 300 MW Power Plant," Applied Energy, vol. 208, pp. 592-606, 2017.

[10] NikhilPachauri, et al., "Two Degree of Freedom PID based Inferential Control of Continuous Bioreactor for Ethanol Production," ISA Transactions, vol. 68, pp. 235-250, 2017.

[11] K. K. Ahn and D. Q. Truong, "Online Tuning Fuzzy PID Controller using Robust Extended Kalman Filter," Jounal of Process Control, vol. 19, pp. 1011-1023, 2009.

[12] C. Cheng and M.-S. Chiu, "Robust PID Controller Design for Nonlinear Processes using JITL Technique," Chemical Engineering Science, vol. 63, pp. 5141-5148, 2008.

[13] S.Grema, et al., "Dynamic Self-Optimizing Control for Oil Reservoir Waterflooding," IFAC-PapersOnLine, vol. 48, pp. 50-55, 2015.

[14] S. Pedersen, et al., "Experimental Study of Stable Surfaces for Anti-Slug Control in Multi-Phase Flow," International Journal of Automation and Computing, vol. 13, pp. 81-88, 2016.

[15] T. Dang, et al., "Efficient Guiding Strategies for Testing of Temporal Properties of Hybrid Systems," in NASA Formal Methods Symposium, 2015, pp. 127-142.

[16] K. Zhang, et al., "Enhancing Fixed-Point Control Robustness for Experimental Non-Contact Scans with the Transverse-Dynamic Force Microscope," in Annual American Control Conference (ACC), Milwaukee, WI, USA, 2018.

[17] Z. Yusuf, "Fuzzy Logic Control for Glycerin Bleaching Temperature Control," Msc of Electrical Engineering, Universiti Teknologi Mara, Shah Alam, 2012.

[18] Z. Yongwei, Q. Fei, L. Jianfeng, W. Lei, and W. Qidi, "Performance Criteria Research on PSO-PID Control Systems," International Conference on Intelligent Computing and Cognitive Informatics (ICICCI), pp. 316-320, 2010.

[19] Z. Mohd Yusoff, et al., "Real Time Steam Temperature Regulation using Self-Tuning Fuzzy PID Controller on Hydro Diffusion Essential Oil Extraction System," International Journal on Smart Sensing \& Intelligent Systems, vol. 6, pp. 2055-2074, 2013.

[20] J. H.Lilly, "Fuzzy Control and Identification": John Wiley \& Sons, Inc., Hoboken, New Jersey, 2010.

[21] S. M. Mousavia, et al., "Evaluating Construction Projects by a New Group Decision-Making Model based on Intuitionistic Fuzzy Logic Concepts," International Journal of Engineering, vol. 28, pp. 1312-1319, 2015.

[22] Y. Zhao, et al., "Distributed Finite-Time Tracking of Multiple Non-Identical Second-Order Nonlinear Systems with Settling Time Estimation," Automatica, vol. 64, pp. 86-93, 2016. 
[23] Z. M. Yusoff, et al., "Implementation of Hybrid Fuzzy plus PID Controller in Real Time Steam Temperature Control," presented at the IEEE 3rd International Conference on System Engineering and Technology, Shah Alam, 2013.

[24] Z. Mohd Yusoff, et al., "Real Time Steam Temperature Regulation using Self-Tuning Fuzzy PID Controller on Hydrodiffusion Essential Oil Extraction System," International Journal on Smart Sensing \& Intelligent Systems, vol. 6, pp. 2055-2074, 2013.

[25] Z. M. Yusoff, et al., "Self- Tuning Fuzzy PID Controller using Online Method in Essential Oil Extraction Process," in 6th International Conference on Computing and Informatics, ICOCI, 2017, pp. 208-214.

[26] Z. M. Yusoff, et al., "Application of Hybrid Fuzzy Plus PID for Steam Temperature Control in Hydro-Diffusion Essential Oil Extraction System," in IEEE 10th International Colloquium on Signal Processing and Its Applications, CSPA Kuala Lumpur, Malaysia, 2014, pp. 163-167.

\section{BIOGRAPHIES OF AUTHORS}
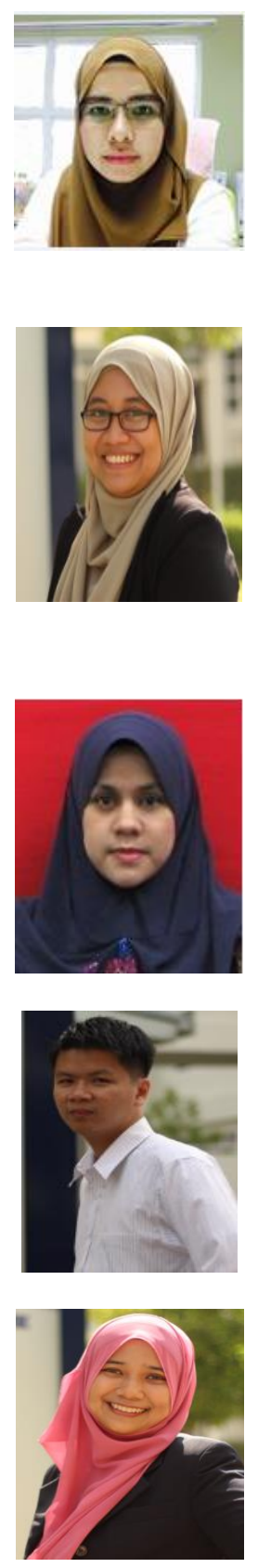

Dr Zakiah Mohd Yusoff is a senior lecturer who is currently working at UITM Pasir Gudang. She received the B. ENG in Electrical Engineering and PhD In Electrical Engineering from UITM Shah Alam, in 2009 and 2014, respectively. In Mei 2014, she joined UITM Pasir Gudang as a teaching staff. Her major interests include process control, system identification, and essential oil extraction system.

Nur Dalila K.A. is currently working as a Lecturer in the Department of System, Faculty of Electrical Engineering, Universiti Teknologi MARA, Johor, Malaysia. She received the Diploma in Electronics and Bachelor of Engineering (Hons) in Electrical Engineering both from Universiti Teknologi MARA (UiTM) and then further Master degree at National University of Singapore (NUS) in 2011. She is now actively doing research projects on educational learning tools and machine learning application. Her current research interests are on LabVIEW modelling and simulation, measurement and sensing technique, Internet of Things and data analytics.

Dr Zuraida Muhammad is a senior lecturer who is currently working at UITM Pulau Pinang. She received the B. ENG in Electrical Engineering and PhD In Electrical Engineering from UITM Shah Alam, in 2009 and 2015, respectively. In February 2015, she joined UITM Pulau Pinang as a teaching staff. Her major interests include process control, system identification, and essential oil extraction system.

Amar Faiz Zainal Abidin received his first degree, M.Eng. (Hons) in Electrical and Electronics Engineering from University of Nottingham, Malaysia and M.Eng. from Universiti Teknologi Malaysia (UTM). He is currently attached as an academic staff with Universiti Teknikal Malaysia Melaka (UTeM). His research interests include multiobjective optimisation and nature-inspired optimisation algorithms.

Noor Fadzilah binti Razali received her first degree, B. Eng. (Hons) in Biomedical Engineering from University of Malaya, Malaysia and M.Eng. also from Universiti of Malaya. She is currently attached as an academic staff with Universiti Teknologi MARA (UiTM). Her research interests include biomedical signal processing and biosensor design 


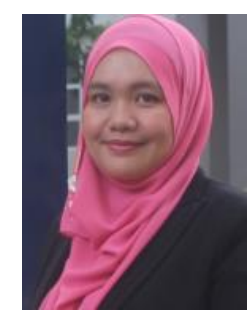

Shakira Azeehan Binti Azli received her first degree, B. Eng. (Hons) in Electrical Engineering from University Teknologi Malaysia, Malaysia and M.Eng. also from Universiti Teknologi Malaysia. She is currently attached as an academic staff with Universiti Teknologi MARA (UiTM). Her research interests include High Volatge and Power System.

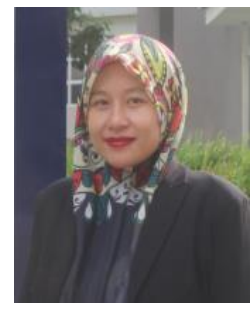

Arni Munira binti Markom was first graduated from Universiti Teknikal Malaysia Melaka (UTeM) in Electronics and Computer Engineering and M.Sc of Microelectronics from Universiti Kebangsaan Malaysia. Then, she is awarded her Doctor of Philosophy (Ph.D) in photonics research area from Universiti Malaya (UM). She is currently a full time researcher and academic staff in Universiti Teknologi MARA (UiTM) Johor. Her research focus on fiber optic amplifiers, pulsed fiber laser and fiber sensors.

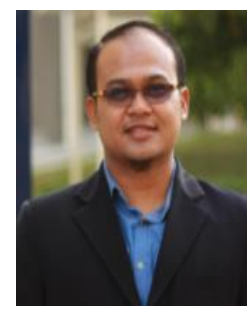

Khairul Kamarudin Bin Hasan received his first degree, B. Eng. (Hons) in Electronic Industry from University Technical Malaysia Melaka, and M.Eng. also from University Technical Malaysia Melaka. He is currently attached as an academic staff with Universiti Teknologi MARA (UiTM). He research interests including Power Electronic Converter, Control System and Wireless Power Transfer. 